\title{
DA ASCESE À DISCIPLINA: A ÉTICA PROTESTANTE E A CONSTITUIÇÃO DO SUJEITO CAPITALISTA*
}

\author{
Walter Guandalini Jr.**
}

\begin{abstract}
RESUMO: Após examinar os pontos de vista de Max Weber e Michel Foucault sobre o processo de formação do "sujeito capitalista", descarta-se a hipótese weberiana de "seleção econômica" dos indivíduos mais adaptados ao modo de produção capitalista. Defende-se a posição de Foucault, para quem essa espécie de indivíduos não é selecionada, mas construída por mecanismos que visam à constituição de sujeitos passíveis de apropriação pelo aparelho de produção com o mínimo de gastos políticos e econômicos e o máximo de aproveitamento produtivo. Essa tarefa não se realiza sem uma rede de poderes, estratégiaș é instituições que se apropriam dos corpos dos indivíduos e regulam suas condutas, ressaltando-se o papel desempenhado pelo Direito nesse processo.
\end{abstract}

A miser sold all that he had, and bought a lump of gold, which he took and buried in a hole dug in the ground by the side of an old wall, and went daily to look at it. One of his workmen, observing his frequent visits to the spot, watched his movements, discovered the secret of the hidden treasure, and, digging down, came to the lump of gold, and stole it. The miser, on his next visit, found the hole empty, and began to tear his hair, and to make loud lamentations. A neighbour, seeing him overcome with grief,

* Paper apresentado como trabalho de conclusão da disciplina Direito e Sociedade, ministrada pelo Prof: Dr. Abili Lázaro Castro Lima, no Programa de Pós-Graduação em Direito da UFPR - Mestrado.

** Mestrando em Direito do Estado na UFPR, advogado. Contato: waltgn@hotmail.com. and learning the cause, said, "Pray do not grieve so; but go and take a stone, and place it in the hole, and fancy that the gold is still lying there. It will do you quite the same service; for when the gold was there, you had it not, as you did not make the slightest use of it. ${ }^{1}$

ESOPO, "The Miser"

1 "Um avarento vendeu tudo o que possuía e comprou um monte de ouro, que enterrou em um buraco cavado no solo ao lado de um velho muro, aonde ia diariamente. Um de seus empregados, tendo reparado em suas freqüentes visitas ao local, observou seus movimentos, descobriu o segredo do tesouro enterrado, e, cavando, encontrou o monte de ouro, que roubou. $\mathrm{O}$ avarento, na visita seguinte, tendo encontrado o buraco vazio, arrancou os cabelos e se lamentou ruidosamente. Um vizinho, 
Guarda-te de pensar que tudo o que possuis é propriedade tua, e de viver como se fosse. Nessa ilusão incorre muita gente que tem crédito. Para te precaveres disso, mantém uma contabilidade exata de tuas despesas e receitas. Se te deres a pena de atentar para os detalhes, isso terá o seguinte efeito benéfico: descobrirás como pequenas despesas se avolumam em grandes quantias e discernirás o que poderia ser poupado e o que poderá sề-lo no futuro.

Benjamin Franklin²

\section{INTRODUÇÃO}

Os dois textos transcritos em epígrafe exprimem duas éticas diferentes. Duas formas de conduta opostas, duas visões antagônicas a respeito do trabalho e do dinheiro. A fábula de Esopo, O Avarento, narra a história de um homem que vende todos os seus bens e enterra o ouro que recebe em troca, mas após certo tempo é roubado. Seu vizinho o recrimina com ironia: não há diferença entre o ouro, uma pedra, ou qualquer outra coisa que se enterre no mesmo local; ter o ouro enterrado é o mesmo que não o ter, já que não se pode fazer uso dele. Percebe-se o ganho material como apenas uma forma de se satisfazer as necessidades do ser humano, não como um fim em si mesmo. A fábula censura a idéia de

vendo-o ser dominado pela aflição, e sabendo o motivo, disse, 'Por favor, não se aflija dessa forma; pegue uma pedra, coloque-a no buraco, e faça de conta que o ouro ainda se encontra lá. Não vai fazer a menor diferença; pois quando o ouro estava lá, você não o tinha, já que não fazia o menor uso dele"” (ESOPO, 1998:34 - tradução livre).

2 O trecho é apenas uma parte de um texto citado por Weber (2004:44), que foi extraído pelo autor de Necessary Hints to Those that Would Be Rich, escrito por Franklin em 1736, e de Advices to a Young Tradesman, de 1748. se guardar o dinheiro que se possui, em vez de se utilizá-lo.

O texto de Benjamin Franklin, por sua vez, é uma exortação ao lucro e ao ganho material, e mais que isso, à poupança e ao resguardo do gozo imediato. Seus "conselhos ao jovem homem de negócios" exprimem uma ética completamente diferente, que trata o lucro não apenas como um fim em si mesmo, mas como um dever moral, conseqüência necessária da habilidade na profissão. Apesar de parecer meramente utilitário, o texto de Franklin expressa uma ética que trata aquelas formas de conduta não só como úteis, mas como um bem. Da leitura das máximas presentes no texto completo (tempo é dinheiro, crédito é dinheiro, o dinheiro é procriador, pague em dia, garanta crédito, pareça honesto, poupe) se percebe "o ser humano em função do ganho como finalidade de vida, não mais o ganho em função do ser humano como meio destinado a satisfazer suas necessidades materiais" (WEBER, 2004:46). A poupança e o nãodesperdício são vistos como uma virtude, devendo o indivíduo viver como se o que ele possui não fosse sua propriedade.

Tem-se, dessa forma, dois textos distintos: o primeiro, representante do "tradicionalismo";," o segundo, da "ética capitalista" (WEBER, 2004:41). A questão que o presente trabalho buscará resolver é: como os indivíduos deixaram de ser "tradicionalistas" para serem "capitalistas"? Weber analisa profundamente

3 Segundo Weber (2004:53), no tradicionalismo “o ser humano não quer 'por natureza' ganhar dinheiro e sempre mais dinheiro, mas simplesmente viver, viver do modo como está habituado a viver e ganhar o necessário para tanto". 
as origens protestantes da ética capitalista e o modo como ela se constituiu, mas a resposta que ele dá a essa questão é simplória. Segundo o autor, "o capitalismo hodierno, dominando de longa data a vida econômica, educa e cria para si mesmo, por via da seleção econômica, os sujeitos econômicos - empresários e operários - de que necessita"4 (WEBER, 2004:48 - grifos no original). A seleção econômica dos indivíduos mais adaptados ao modo de produção capitalista conforme a lei de mercado seria a causa, portanto, da superação da ética tradicional pela ética capitalista.

Os estudos de Michel Foucault sobre o poder disciplinar parecem fornecer uma resposta mais adequada à questão. A partir desses estudos poderíamos afirmar que não foi a mera seleção econômica que garantiu a sobrevivência da ética calvinista em sua forma capitalista; em verdade, o surgimento, a partir do século XVIII, de uma nova forma de distribuição espacial e social da riqueza tornou necessária a criação de novos métodos de controle social (FOUCAULT, 2001:101), que não apenas "selecionaram" os indivíduos mais adequados ao capitalismo, mas criaram a espécie de indivíduos de que ele necessitava. Parte-se da hipótese, então, de que foram tecnologias de poder e instituições bastante

4 O próprio Weber reconhece, já na frase seguinte, as limitações do conceito de "seleção" como meio de explicação de fenômenos históricos já que, para poderem ser "selecionadas", essas formas de conduta de vida têm, primeiro, de emergir como um modo de vida portado por grupo sociais. No entanto, após essa emergência (cuja causa é, para Weber, o protestantismo calvinista), permanece a hipótese da seleção econômica como explicação para a predominância da ética capitalista na atualidade. concretas que constituíram um determinado tipo de sujeito, útil ao desenvolvimento do capitalismo. E, tendo-se espalhado em rede por todo o corpo social, foram capazes de substituir as formas de conduta ainda baseadas no tradicionalismo.

Analisemos, portanto, a formação e os elementos do espírito capitalista segundo Weber (2004) para, em seguida, verificarmos o modo como se deu a constituição de sujeitos capitalistas na sociedade disciplinar, seguindo a análise de Foucault (2000, 2004b). Após, examinaremos o relevante papel desempenhado pelo direito nesse processo.

\section{A ASCESE PROTESTANTE E A FORMAÇÃO DO ESPÍRITO DO CAPITALISMO}

Weber inicia seu estudo a partir da constatação da existência de uma relação entre as práticas decorrentes de uma determinada crença religiosa e diferentes posições (principalmente econômicas) dos indivíduos no estrato social: de modo geral, no início do século $\mathrm{XX}$, os proprietários do capital e as camadas superiores da mão-deobra qualificada eram predominantemente protestantes (2004:29). A partir dessa constatação empírica, Weber formula a hipótese de que pode haver uma relação entre "estranhamento do mundo" (compreendido como o predomínio de interesses religiosos na conduta de vida - WEBER, 2004:35), ascese e devoção eclesial, por um lado, e formas de conduta capitalistas, por outro. E é a relação entre esses fatores que o autor procura desvendar.

Mas antes é necessário compreender o "espírito" do capitalismo, para então investigar 
a possibilidade de a ética protestante ser uma de suas causas. Em primeiro lugar, o espírito do capitalismo não é apenas uma ética que trata o aumento de riquezas como um fim em si mesmo. Não se trata apenas de "perspicácia nos negócios" ou de busca da riqueza, mas de um ethos cuja violação é tratada como falta com o dever e violação moral. A característica específica do espírito capitalista não é a cobiça - afinal, não se pode empregar como operários os representantes de um livre arbítrio indisciplinado, nem é útil para o capitalismo o homem de negócios sem escrúpulos (WEBER, 2004:50). O que distingue o espírito capitalista não é o simples desejo de lucro, mas a idéia da profissão como um dever, a disposição para executar o trabalho como fim absoluto em si mesmo, como vocação. Dessa forma; o espírito do capitalismo pode ser provisoriamente definido como a disposição que, no interior de uma profissão vista como vocação, de forma sistemática ambiciona o ganho legítimo e racional (WEBER, 2004:57). ${ }^{5}$

Segundo Weber (2004:72), essa idéia de profissão como vocação surge, em primeiro lugar, no luteranismo. De acordo com a dogmática luterana, o único meio de viver que agrada a Deus não está em suplantar a

5 Vale notar que, para Weber (2004:60), é essa a força motriz do desenvolvimento capitalista, e não a acumulação do capital ou o grau de desenvolvimento das forças produtivas (no que contraria a hipótese de Marx), já que o espírito capitalista cria o capital onde ele antes não existia, ao passo que a existência de capital não é capaz de criar o espírito capitalista, nem suficiente para assegurar, por si só, o desenvolvimento do capitalismo - o que não significa, obviamente, que o acúmulo de metais seja indiferente ou que esse espírito seja a única causa do surgimento do capitalismo. moralidade intramundana pela ascese monástica (a solução do catolicismo medieval), mas em cumprir adequadamente os deveres intramundanos, tratados como vocação profissional do indivíduo. O trabalho profissional mundano é visto como expressão de amor ao próximo e único modo de agradar a Deus, já que é o desígnio divino que ordena ao indivíduo ocupar uma determinada posição na vida.

Entretanto, apesar da importância da valorização do trabalho intramundano profissional para o desenvolvimento do espírito capitalista, a doutrina luterana permanece tradicionalista. Conforme a ordem histórica objetiva em que o indivíduo foi inserido por Deus se torna uma emanação direta da vontade divina, o luteranismo se dirige cada vez mais à idéia tradicionalista de que o indivíduo deve permanecer na profissão e estamento em que Deus o colocou, e manter sua ambição terrena dentro dos limites dessa posição na vida que the foi dada - o que acaba por enfraquecer os efeitos práticos da idéia do trabalho profissional como missão.

Já o calvinismo ${ }^{6}$ gera efeitos muito importantes para a constituição do espírito capitalista. Uma de suas principais características é a desglorificação da criatura: não é Deus que existe para os seres humanos, mas os seres humanos que existem para Deus, e todo acontecimento deve ser sentido exclusivamente

6 Além do calvinismo, Weber analisa o pietismo, o metodismo e as seitas batistas e anabatistas. Como essas doutrinas têm muitos pontos em comum e geram efeitos bastante similares, nos permitimos, como Weber, "tratar o protestantismo ascético como um bloco" (2004:141 - grifo no original), tomando o calvinismo como modelo. 
como um meio para a Sua autoglorificação. Ainda, toda criatura está separada de Deus por um abismo intransponível, e tudo o que se sabe é que uma parte da humanidade será salva, e a outra condenada. Supor que mérito ou culpa humana contribuem para fixar esse desígnio seria encarar as decisões absolutamente livres de Deus como passíveis de alteração por obra humana, o que é impossível - "a graça de Deus é tão imperdível por aqueles a quem foi concedida como inàcessível àqueles a quem foi recusada" (WEBER, 2004:94). A doutrina da predestinação gera, assim, o isolamento do indivíduo, que não pode ser ajudado por nada nem ninguém.

Esses fatores levam à negação, pelo puritanismo, de todos os elementos sensoriais e sentimentais na cultura e na religiosidade (pois são inúteis à salvação e fomentam a divinização da criatura). Assim, o "amor ao próximo" assume uma conotação impessoal, passando a ser visto como serviço prestado à conformação racional do cosmos social, o que diferencia a concepção calvinista de vocação profissional da concepção luterana.

Além disso, com a doutrina da predestinação, o único meio que o indivíduo tem de se saber eleito é a "firme confiança de quem crê e persevera" (WEBER, 2004:100). Porém, como Weber não se cansa de alertar, deve-se distinguir o que uma religião almejava como ideal do impacto efetivamente causado em seus adeptos. Na prática, os seguidores do calvinismo precisavam de um sinal mais concreto da salvação: torna-se, então, um dever considerar-se eleito e repudiar qualquer dúvida como tentação, e o trabalho sem descanso é visto como o melhor meio para se evitar essa insegurança (que é sinal da danação).

Em termos práticos, isso se traduz numa "auto-inspeção sistemática da conduta de vida que, a cada instante, é obrigada a enfrentar a alternativa: eleito ou condenado?" (WEBER, 2004:105). O Deus do calvinismo não se contentava com "boas obras" isoladas; a práxis ética se torna um método de condução da vida que mantém o controle contínuo do estado de graça, o que leva a uma racionalização da vida intramundana e uma conformação racional da vida ética em seu conjunto.

Nesse modo de vida ascético a riqueza é uma ameaça, pois traz consigo o perigo do relaxamento. O ócio e o prazer são proibidos, pois a falta de vontade de trabalhar é sintoma da ausência do estado de graça. $O$ desperdício de tempo é o pior dos pecados, pois representa menos tempo dedicado à glorificação de Deus. O trabalho duro e continuado é um modo de se preservar das tentações que afastam o indivíduo da salvação, mas é também a finalidade da vida, prescrita por Deus (que confere a todos uma vocação), sendo que o valor atribuído ao trabalho por Deus é inferido de critérios morais e de sua importância para a coletividade, mas também - e principalmente - da sua capacidade de dar lucro, de modo que, se decorre do desempenho no dever vocacional, a riqueza é considerada moralmente lícita.

Assim, a ascese protestante intramundana liberou o enriquecimento dos entraves da ética tradicionalista, valorizando o lucro e o trabalho profissional continuado e sistemático como meios de comprovação da fé. O estrangulamento do consumo e a desobstrução do lucro levam à acumulação de capital 
mediante coerção ascéticà à poupança, o que favorece o seu emprego produtivo (reinvestimento nos meios de produção).

Entretanto, uma vez acumuladas as riquezas, abandonavam-se os ideais puritanos. Ocorre, assim, uma reterritorialização (DELEUZE e GUATTARI, 2002e:224) da ascese puritana, cujo fim deixa de ser a glorificação de Deus e passa a ser simplesmente o lucro privado. O protestantismo, que no contexto histórico em que surgiu era uma possível linha de fuga, relativamente desterritorializada (pois resultado de uma escolha pessoal e possibilidade de libertação - espiritual, intelectual, econômica, política), é ressignificado no capitalismo, que the atribui um novo território, segmentarizado e já pleno de significado - a ascese religiosa se transforma em virtude profissional. Surge, então, uma ética estritamente capitalista, que, de um lado, legitima o lucro do empregador burguês, e, do outro, põe à sua disposição trabalhadores sóbrios, eficientes e "aferrados ao trabalho como finalidade de sua vida, querida por Deus" (WEBER, 2004:161).

Compreendidos os fundamentos religiosos e o processo de formação do espírito do capitalismo, reaparece a questão proposta na introdução do trabalho: como ocorre a difusão desse espírito na sociedade? Weber sugere a hipótese da seleção econômica como fator explicativo da predominância da ética capitalista na atualidade, mas essa ainda não é uma resposta suficiente. Afinal, no modo de vida tradicional a única preocupação era "viver do modo como [se] está habituado a viver e ganhar o necessário para tanto" (WEBER, 2004:53), uma forma de conduta incompatível com a adaptação ética em busca de melhores posições no mercado (principalmente no que se refere ao trabalhador). Não parece, portanto, que a mera seleção econômica seja suficiente para difundir a ética capitalista. Segundo Michel Foucault, os indivíduos que se conduziam do modo mais adequado para o desenvolvimento do capitalismo não foram apenas "selecionados" pelo mercado, mas constituídos por uma rede de instituições e tecnologias de poder que, mediante processos de normalização, criaram formas de subjetividade que acabaram por substituir as formas de conduta tradicionais por um tipo de sujeito marcado pela ética capitalista. Esse argumento será analisado mais detidamente no item seguinte.

\section{A DISCIPLINA E A CONSTITUIÇÃO DO SUJEITO CAPITALISTA}

A princípio, a intuição de Weber estava correta: a ética capitalista não surge do nada, mas aparece primeiro em certos grupos sociais. Contudo, ela também não se espalha sem motivos, mas decorre de um conjunto de processos, poderes e instituições que conformam a conduta dos indivíduos de modo a constituir "sujeitos capitalistas".

Com a explosão demográfica e o crescimento do aparelho de produção no século XVIII, passa a existir a necessidade econômica de ordenação das multiplicidades humanas. Surge, nesse período, uma forma de riqueza que é investida em uma materialidade não-monetária (mercadorias, estoques, máquinas, oficinas etc.), o que a deixa muito exposta à depredação. À medida que se concentram geograficamente as forças de produção, tenta-se encontrar meios de tirar delas o máximo de vantagens econômicas 
com a neutralização de seus inconvenientes, o que se dá com a proteção dos materiais e ferramentas (do roubo e da destruição) e a dominação das forças de trabalho (evitando a preguiça e as agitações políticas), por meio de mecanismos de controle que permitam a proteção dessa fortuna. É nesse contexto que surgem as disciplinas, "métodos que permitem o controle minucioso das operações do corpo, que realizam a sujeição constante de suas forças e lhes impõem uma relação de docilidade-utilidade" (FOUCAULT, 2004b:118), reduzindo a força do corpo como força política e maximizando-a como força econômica; dissociando o poder do corpo, de modo a tornar o exercício do poder o menos custoso e mais efetivo possível (economicamente e politicamente), e ligando-o ao rendimento dos aparelhos no interior do qual se exerce (de produção, escolar, militar etc. - fazendo crescer simultaneamente a docilidade e utilidade dos elementos do sistema).

Para desempenhar essa tarefa, a disciplina é obrigada a cumprir determinadas funções que acabam gerando no indivíduo efeitos de comportamento similares aos gerados pela ética protestante. Contudo, esse comportamento não é resultado de uma opção de vida pessoal, nem da seleção imposta pela "concorrência de mercado", mas de mecanismos e instituições que, incidindo diretamente sobre o corpo dos indivíduos, constituem formas de comportamento adequadas a esses objetivos.

Assim, a disciplina constitui, mediante técnicas específicas, uma individualidade dotada de basicamente quatro características: com a técnica da "construção de quadros", constitui uma individualidade celular; com a "prescrição de manobras", uma individualidade orgânica; pela "imposição de exercícios", uma individualidade genética; e pela "organização de táticas", uma individualidade combinatória.

Em primeiro lugar, trata-se de organizar o múltiplo, transformando as multidões inúteis e perigosas em multiplicidades organizadas, das quais se torna possível extrair o máximo de efeitos úteis. $\mathrm{O}$ poder disciplinar liga o singular ao múltiplo, permitindo a caracterização do indivíduo como indivíduo e a sua colocação na ordem de uma multiplicidade organizada (FOUCAULT, 2004b:127). Para isso ele utiliza várias táticas de poder: a cerca permite a especificação de um local heterogêneo a todos os outros e fechado em si mesmo, formando um encarceramento que permite controlar as massas desorganizadas; pelo quadriculamento se divide esse espaço fechado em tantas parcelas quantos corpos há a repartir, organizando-se um espaço analítico que, ao mesmo tempo em que interrompe a circulação difusa e inútil, permite saber onde se encontra cada indivíduo; a regra das localizações funcionais procura criar um espaço útil, em que se articulem a distribuição dos corpos, a arrumação especial do aparelho de produção e as diversas formas de atividade útil na distribuição dos postos, fazendo com que aquele espaço parcelado indique imediatamente a função de cada elemento no sistema; finalmente, com a tática da posição na fila cada um se define pelo lugar que ocupa numa determinada classificação, individualizando-se os corpos por meio de uma localização que os distribui e faz circular numa rede de relações. Desse modo, organizam-se os 
indivíduos em "quadros vivos" que transformam as multidões confusas em multiplicidades organizadas, passíveis de serem utilizadas nas instituições dos aparelhos de produção (fábrica), educacional (escola), militar (quartel), carcerário (prisão) etc. A constituição de uma individualidade celular é a condição necessária para o controle e uso de elementos distintos em uma multiplicidade, e é por meio dessas táticas políticas que se constitui o sujeito individual e isolado que Weber havia identificado como resultado da ética calvinista.

Mas não basta organizar as multiplicidades e controlar a localização dos elementos em uma multiplicidade; afinal, o corpo "mecânico" é também um corpo "orgânico", cujo comportamento deve ser conhecido, controlado e utilizado. A decomposição fracionada das atividades permite o controle cada vez mais preciso do comportamento individual, e isso é realizado mediante as seguintes táticas: o controle do horário evita o desperdício do tempo, mas garante também a qualidade do tempo empregado, constituindo um tempo integralmente útil; a elaboração temporal do ato por meio de um "programa" permite o controle a partir do interior do próprio ato, em uma trama que organiza as fases dos movimentos ao longo de todo o seu encadeamento; com a articulação entre corpo e gesto se impõe a melhor relação entre um gesto e a atitude global do corpo, condição de utilidade, eficácia e rapidez; com a articulação corpo-objeto, estabelece-se uma engrenagem que permite articular o corpo ao aparelho de produção; e o princípio da utilização exaustiva organiza uma economia positiva que busca utilizar cada vez mais o tempo, por um lado, vedando a ociosidade e o desperdício de tempo, mas, por outro, extraindo dele cada vez mais instantes disponíveis e forças úteis, mediante seu infinito fracionamento. Assim, o poder disciplinar prescreve "manobras" de modo a obter controle sobre o mínimo movimento do indivíduo, microscopicamente fracionado. Como afirma Foucault (2004b:120), "para o homem disciplinado, como para o verdadeiro crente, nenhum detalhe é indiferente, mas menos pelo sentido que nele se esconde que pela entrada que aí encontra o poder que quer apanhá-lo", transformando seu comportamento em método de condução da vida que, como no calvinismo, controla continuamente o "estado de graça" (WEBER, 2004:112).

Além do espaço e do comportamento dos indivíduos, o poder disciplinar controla também o seu tempo. A disciplina constitui uma individualidade genética por meio do exercício, que impõe ao corpo tarefas repetitivas, mas sempre graduadas, permitindo uma perpétua caracterização do indivíduo quanto ao seu termo final, em relação aos outros indivíduos, e em relação a um determinado tipo de percurso, observando-o e qualificando-o nesse continuum. Isso por quatro processos: com a decomposição do tempo, que é dividido em segmentos dos quais cada um deve chegar a um termo específico; com a organização analítica dos segmentos em que o tempo é dividido, em uma sucessão de elementos simples combinados segundo uma complexidade crescente; com a prova, que representa a finalização de cada segmento temporal, e tem a tríplice função de indicar se o indivíduo atingiu o nível estatutário, garantir que sua aprendizagem está em conformidade com a dos outros e diferenciar as capacidades de 
cada indivíduo; estabelecendo séries de séries, de modo que cada indivíduo se encontra numa série temporal, que define especificamente seu nível ou categoria. Trata-se de uma nova técnica de apropriação do tempo, que transforma o passar do tempo em oportunidade de capitalização e aumento de utilidade dos indivíduos. Nas palavras de Foucault, "recolhe-se a dispersão temporal para lucrar com isso e conserva-se o domínio de uma duração que escapa. O poder se articula diretamente sobre o tempo; realiza o controle dele e garante a sua utilização" (2004b:136). Com o controle do tempo (pela imposição de exercícios) se constitui uma individualidade genética, que permite caracterizar os indivíduos de acordo com o nível em que se encontram em uma série e os utilizar de acordo com esse nível, que aumenta continuamente. Como no calvinismo, também na sociedade disciplinar o maior pecado é o desperdício de tempo; não porque deveria ser utilizado para a glorificação de Deus ou porque o ócio sujeita o indivíduo ao pecado, mas porque tempo perdido representa uma redução da capitalização da utilidade da força de trabalho, o que prejudica a sua utilização pelo aparelho de produção.

Finalmente, além de repartir os corpos, controlar suas atividades, extrair e acumular o seu tempo, a disciplina busca compor forças para se obter um aparelho eficiente. O objetivo é constituir uma força produtiva cujo efeito seja superior à soma das forças elementares que a compõem, o que se faz por meio da tática - "arte de construir, com os corpos localizados, atividades codificadas e aptidões formadas, aparelhos em que o produto das diferentes forças se encontra majorado por sua combinação calculada"
(FOUCAULT, 2004b:141). Assim, o corpo se torna um elemento em articulação, e o que o define não são suas características individuais, mas o lugar que ele ocupa na ordem da multiplicidade, o que o torna peça de uma máquina multissegmentar; também o tempo passa a ser visto como elemento em articulação, com a disciplina combinando as várias séries cronológicas para formar um tempo composto, de maneira a se poder extrair a máxima quantidade de forças de cada indivíduo no tempo adequado, combinando-as num resultado ótimo; ainda, a combinação eficiente das forças exige um sistema preciso de comando, de modo a não se desperdiçar tempo e forças explicando ordens, que devem apenas provocar o comportamento desejado. Gera-se, assim, o efeito de obediência, necessário para a melhor organização das forças produtivas, o que, mesmo sem que o trabalho seja apresentado como desejado diretamente por Deus, põe à disposição do empresário os mesmos trabalhadores sóbrios e eficientes que Weber já havia identificado (2004:161), e que vêem o trabalho como dever moral.

O sucesso do poder disciplinar e o efetivo cumprimento das funções que acabam de ser examinadas dependem de instrumentos bastante simples: a vigilância hierárquica, a sanção normalizadora e o exame.

A vigilância hierárquica cria um aparelho cujas técnicas que permitem ver induzem a efeitos de poder, tornando os meios de coerção visíveis àqueles sobre quem se aplicam. Trata-se de um aparelho de observação, registro e treinamento, em que "um ponto central seria ao mesmo tempo fonte de luz que iluminasse todas as coisas, e lugar de convergência para tudo o que 
deve ser sabido: olho perfeito a que nada escapa e centro em direção ao qual todos os olhares convergem" (FOUCAULT, 2004:146). Com o desencantamento do mundo e a reterritorialização da ética protestante, o fundamento do controle contínuo necessário para a constituição do sujeito capitalista deixa de ser a onisciência divina para ser a torre do Panóptico, ${ }^{7}$ arquitetura ideal que serve de modelo a um sem-número de instituições reais como a escola, o hospital, o exército e a prisão - locais onde se desenrola todo esse teatro de estratégias, e instrumentos de disciplinamento que constituem o "sujeito capitalista".

Com a sanção normalizadora as disciplinas estabelecem uma infra-penalidade, tornando penalizáveis as condutas mais irrelevantes, e dando uma função punitiva a elementos aparentemente irrelevantes do aparelho disciplinar. "Para o homem disciplinado, como para o verdadeiro crente,

7 "O Panóptico de Bentham é a figura arquitetural dessa composição. O princípio é conhecido: na periferia uma construção em anel; no centro, uma torre; esta é vazada de largas janelas que se abrem sobre a face interna do anel; a construção periférica é dividida em celas, cada uma atravessando toda a espessura da construção; elas têm duas janelas, uma para o interior, correspondendo às janelas da torre; outra, que dá para o exterior, permite que a luz atravesse a cela de lado a lado. Basta então colocar um vigia na torre central, e em cada cela trancar um louco, um doente, um condenado, um operário ou um escolar. Pelo efeito da contraluz, pode-se perceber da torre, recortando-se exatamente sobre a claridade, as pequenas silhuetas cativas nas celas da periferia. [...] Daí o efeito mais importante do Panóptico: induzir no detento um estado consciente e permanente de visibilidade que assegura o funcionamento automático do poder. Fazer com que a vigilância seja permanente em seus efeitos, mesmo se é descontínua em sua ação" (FOUCAULT, 2004b:165 - grifos no original). nenhum detalhe é indiferente" (FOUCAULT, 2004b:120). O que pertence à penalidade disciplinar é o desvio da norma, de modo que o castigo disciplinar tem a função de reduzir os desvios, operando por um sistema de gratificação-sanção. Esse mecanismo permite a qualificação e quantificação do comportamento, o que possibilita a hierarquização dos indivíduos na escala de "maus" a "bons". Essa hierarquização, ao mesmo tempo em que marca os desvios e hierarquiza as qualidades, castiga e recompensa. A separação entre os "escolhidos" (que trabalham com vigor, repudiam o ócio, renunciam aos prazeres etc.) e os "danados" (preguiçosos, vagabundos etc.) do calvinismo é transformada, na sociedade disciplinar, pela sanção normalizadora, em divisão entre o "normal" e o "anormal" - com base nos mesmos critérios.

O exame, combinando vigilância hierárquica e sanção normalizadora, faz a individualidade entrar num campo de registro e acumulação documentária, situando os indivíduos em uma rede de anotações escritas, o que simultaneamente constitui o indivíduo como objeto do saber e a população como espaço de avaliação do fenômeno global, transformando cada indivíduo em um caso, resultado do encontro de feixes de saber-poder, simultaneamente objeto para o conhecimento e tomada para o poder (FOUCAULT, 2004:160).

Percebe-se, então, que a formação de "sujeitoș capitalistas" é resultado de um processo muito mais complexo que a mera seleção econômica dos mais aptos. Mais complexo e mais árduo, pois necessita de uma rede de poderes, estratégias e instituições que se apropriam dos corpos dos-indivíduos, regulando suas condutas, com o objetivo de fabricar um tipo de subjetividade necessário 
para aquele estágio de desenvolvimento do capitalismo.

A disciplina é diferente do ascetismo de tipo monástico, que tem por função realizar renúncias mais do que aumentos de utilidade e que, se implica obediência, tem como fim principal um aumento do domínio de cada um sobre seu próprio corpo (FOUCAULT, 2004b:119). No entanto, desempenha funções bastante similares às desempenhadas pela ascese intramundana do protestantismo, gerando efeitos igualmente úteis para o desenvolvimento do Capitalismo. Por diferentes meios, ambos contribuem para a formação de um sujeito que encara o trabalho como vocação, exerce um controle contínuo, permanente e metódico sobre si mesmo, e despreza o desperdício de tempo e os prazeres mundanos. A disciplina, porém, é muito mais eficiente, pois conta com uma rede de instituições e estratégias políticas, eśpalhadas na sociedade, que fabricam, pela força, os indivíduos com as características necessárias. E o direito também desempenhou um importante papel nesse processo, como veremos no próximo item.

\section{O DIREITO DISCIPLINADOR}

Apesar dos inúmeros debates existentes sobre a relação entre o poder soberano (direito) e o poder normalizador (disciplina e biopoder) na obra de Foucault, todos os estudos sobre o tema que se dedicam a examinar o direito mais detidamente encontram-no indissociavelmente imbricado com formas de poder disciplinar. ${ }^{8}$

8 Por todos, a obra de Ricardo Fonseca, que apresenta também um resumo das diversas posições a respeito da questão (2002:116).
A começar pelo estudo de Fonseca (2002), que encontra diversas manifestações do poder disciplinar no Direito do Trabalho. Em primeiro lugar, no conceito de subordinação jurídica. Apesar de ser considerado pela maioria dos doutrinadores o marco mais característico da relação de emprego, o conceito nunca pôde ser definido positivamente, em seu conteúdo, mas apenas a partir de limitações negativas ao poder do empregador sobre o empregado, a ponto de Fonseca poder caracterizá-lo, a partir de elementos da própria doutrina, como "tudo o que o empregador determinar ao empregado, que esteja dentro dos limites da atividade econômica da empresa, que não seja crime, não o humilhe e não o coloque em situação de risco físico" (2002:137). Como demonstra o autor, o direito, na verdade, não cria o conceito de "subordinação jurídica"; apenas domestica uma situação de fato que lhe preexistia, traçando os limites formais de uma relação de subordinação real - limites que informam o ponto até o qual esse poder pode ser exercido licitamente. Assim, o direito torna lícita e legítima a submissão do empregado ao controle contínuo por parte do empregador, enredando-o "numa teia de vigilância constante, num procedimento de exame contínuo, num mecanismo de sanção normalizadora de aplicação intermitente" (FONSECA, 2002:139).

O Direito do Trabalho também disciplina por meio do conceito de jus variandi, exceção à regra geral de imutabilidade do contrato de trabalho (art. 468 CLT), que pode ser aplicado para a melhor efetivação dos fins da empresa. Com o jus variandi, o empregador se aproveita do espaço de indeterminação do conteúdo do contrato para exercer uma vigilância hierárquica sobre o empregado 
(FONSECA, 2002:143), controlando suas férias, seu horário de trabalho, seu desempenho no serviço e sua obediência, transformando-o no "sujeito trabalhador" necessário ao desenrolar das atividades da empresa.

Além disso, com a consagração do poder regulamentar da empresa como fonte primária do Direito do Trabalho (enunciado 51, TST) e a faculdade, conferida ao empregador pelo $\S 2^{\circ}$ do art. 461 da CLT, de estabelecer os critérios de promoção por merecimento dos empregados, o empresário passa a ter o poder de definir uma regra de avaliação dos trabalhadores, sujeitando-os a um padrão normal a partir do qual eles podem ser punidos ou recompensados (FONSECA, 2002:149). Esses dispositivos são complementados com o reconhecimento, ao empregador (decorrência da subordinação jurídica), de um poder punitivo sobre as condutas dos empregados - o que evidencia a presença oculta, nos meandros da relação jurídica de emprego, da sanção normalizadora.

Entretanto, o poder disciplinar não é veiculado pelo direito apenas nos interstícios do texto legal. Como percebe Fonseca (2002:153), há casos em que a lei se dedica expressamente a permitir o controle do corpo do trabalhador pelo empregado, o que ocorre mais claramente no art. 482 da CLT, que prevê as hipóteses de rescisão do contrato de trabalho por justa causa. ${ }^{9}$ Todas as condutas

9 Ato de improbidade; incontinência de conduta ou mau procedimento; negociação habitual sem permissão do empregador; condenação criminal do empregado; desídia no desempenho das funções; embriaguez habitual; violação de segredo da empresa; indisciplina ou insubordinação; abandono de emprego; ato lesivo da honra ou boa fama ou ofensa física praticada no serviço, inclusive contra o empregador; e prática constante de jogos de azar. previstas no dispositivo têm basicamente três finalidades, podendo também se encontrar em um meio-termo entre esses grupos (FONSECA, 2002:154): resguardar a disciplina no trabalho, garantir a lealdade para com o patrão e controlar o corpo do trabalhador como indivíduo. Ao permitir a dispensa do empregado em qualquer desses casos, a lei confere ao detentor do capital o poder de controlar completamente a conduta do indivíduo, inclusive fora do espaço de produção, tornando lícita a incidência de um poder sobre o corpo que acaba por constituir, pela força (assegurada e legitimada pela coercitividade do direito), o tipo de sujeito passível de ser aproveitado no aparelho de produção, em prol do capitalismo. ${ }^{10}$

O Direito do Trabalho não é o único segmento em que o direito é perpassado pela disciplina; outro âmbito de íntima ligação entre o direito e a disciplina é representado, emblematicamente, por um corpus legislativo atualizado no período em que foi criada a CLT (que data de 1943), quando o Brasil deixava para trás o capitalismo agrário de exportação (e, com ele, formas arcaicas de exploração e dominação) e entrava com ímpeto no capitalismo industrial, necessitando, mais do que nunca, de "sujeitos trabalhadores" imbuídos do espírito capitalista e aptos a desempenhar adequadamente sua função no interior da fábrica. Trata-se do Direito Penal.

Em primeiro lugar, temos a tipificação, pelo Código Penal (cuja parte especial data de 1940), de condutas como "paralisação do trabalho" (arts. 200 e 201), e "sabotagem"

${ }^{10}$ Para uma análise mais detalhada de cada uma das condutas que ensejam a dispensa por justa causa, consultar a obra de Fonseca (2002), p.155 e segs. 
(art. 202), formas de proteger os meios de produção no início do processo de industrialização do país, quando a riqueza começa a ser investida em uma materialidade não-monetária (mercadorias, estoques, máquinas, oficinas etc.) exposta à depredação (conforme visto anteriormente). Porém, o espaço onde o Direito Penal se torna mais claramente disciplinar é o Decreto-lei n. ${ }^{\circ} 3.688 /$ 1941, que dispõe sobre as contravenções penais. Esse dispositivo, no capítulo VII de sua Parte Especial (contravenções relativas à polícia dos costumes), proíbe todo tipo de "mau comportamento", punindo com multa e prisão simples uma série de condutas contrárias àquele espírito de isolamento, controle metódico da vida e valorização do trabalho típico da ética capitalista, e cujo principal defeito era tornar os indivíduos inúteis ou indóceis para a exploração capitalista. Nesse sentido, a proibição da vadiagem de quem fosse "válido para o trabalho" (art. 59), a tipificação da mendicância (art. 60), a proibição da embriaguez em público "de modo que cause escândalo" (art. 62) e até mesmo a simples perturbação da tranqüilidade (art. 65); todas essas condutas seriam, certamente, reprovadas pelo Deus calvinista, que lhes reservaria o inferno e a danação. $\mathrm{Na}$ Lei das Contravenções, no entanto, o motivo da reprovação já havia sido reterritorializado, tendo deixado de ser religioso ou moral: trata-se, tão-somente, de vedar toda espécie de conduta que impeça a transformação dos indivíduos em corpos úteis e dóceis, passíveis de utilização no aparelho produtivo em prol do desenvolvimento capitalista.

É certo que atualmente esses dispositivos não são mais aplicados nos tribunais: após setenta anos de capitalismo industrial e financeiro, essas condutas já se tornaram "anormais" - "homens de bem" não se entregam à mendicância ou à embriaguez pública. Porém, no momento em que se dava início ao capitalismo industrial no Brasil, era de fundamental importância estabelecer uma linha clara de demarcação entre o "normal" e o "anormal", visando à constituição de sujeitos cuja conduta os tornasse úteis e dóceis para a utilização no aparelho de produção, de modo que os dispositivos analisados se revestiram de crucial importância naquele momento histórico. Bem o demonstra a censura, em 1940, pelo Departamento de Imprensa e Propaganda, da canção "O Bonde São Januário", de autoria de Ataulfo Alves e Wilson Batista. A letra original dizia: "o bonde São Januário/ leva mais um sócio otário/ eu que não vou trabalhar"; acusada pelo DIP de promover a vadiagem, a canção só foi liberada para gravação de Ciro Monteiro com uma alteração na letra que mudou completamente o seu sentido: "o bonde São Januário/ leva mais um operário/ sou eu que vou trabalhar".

Há, ainda, inúmeros outros casos em que se pode perceber a íntima relação entre o direito e a disciplina, e o importante papel desempenhado pelo direito na constituição do "sujeito capitalista". ${ }^{11}$ Mas apenas os exemplos analisados já demonstram suficientemente a relevância do direito no processo de constituição do sujeito

${ }^{11}$ Por exemplo, o art. $4^{\circ}$, IV, do Código Civil que, ao considerar relativamente incapazes os pródigos, provoca resultados similares aos da ética protestante, coagindo os indivíduos à poupança mas em um grau de exigência bem mais suave que a proibição do gozo de bens terrenos típica do calvinismo. 
capitalista, como mais uma dentre as várias instituições e práticas de poder que contribuíram para a construção de um indivíduo útil e dócil o suficiente para o aparelho de produção.

\section{CONCLUSÃO}

Analisamos neste artigo a reterritorialização da ascese protestante, sua transformação em ética capitalista, e os meios de que ela se utilizou para substituir o tradicionalismo. Mediante a disciplina se constitui a espécie de sujeito necessária ao desenvolvimento do capitalismo: um sujeito que vê no trabalho a realização do fim de sua vida; que assume uma forma de conduta metódica e racional; que exerce continuamente um controle sobre si mesmo, de modo a não se afastar das formas de conduta consideradas normais; que não vê com bons olhos o desperdício de tempo, considerado moralmente mau; que enxerga a riqueza como moralmente legítima, principalmente se for resultado do trabalho desempenhado como vocação; que despreza os gastos em prazeres mundanos, e concebe a poupança e o reinvestimento na produção como sendo as únicas destinações racionais a que pode dar o seu dinheiro.

Como vimos, porém, esse tipo de sujeito não se constrói sem esforço. É necessário todo um conjunto de mecanismos, instrumentos, práticas e instituições que, pela força, constituem indivíduos cujas condutas são adequadas a esses padrões. Descarta-se, assim, a hipótese de Weber, segundo a qual a mera seleção econômica seria suficiente para o predomínio, na atualidade, de indivíduos agindo conforme a ética capitalista. De fato, como afirma Foucault, essa espécie de indivíduos é construída por mecanismos de subjetivação, em uma política do corpo que tem por objetivo final a constituição de sujeitos úteis e dóceis, passíveis de apropriação pelo aparelho de produção com o mínimo de gastos políticos e econômicos e o máximo de aproveitamento. Dessa forma, pode-se utilizar a força de trabalho necessária com o mínimo de riscos para a riqueza acumulada, desde o século XVIII investida de forma nãomonetária em matéria-prima, estoques de mercadorias, máquinas, oficinas etc.

Finalmente, verificamos que o direito pôde oferecer uma importante contribuição nesse esforço de construção de um sujeito "disciplinado" (capitalista). Por meio da análise do Direito do Trabalho e do Direito Penal, pudemos perceber que o direito, ao retransmitir, mediante os instrumentos descritos por Michel Foucault, formas de disciplinamento do indivíduo, empresta ao poder normalizador o próprio poder de que dispõe (o poder soberano e a coerção estatal centralizada), contribuindo decisivamente para a constituição do sujeito capitalista e, assim, para o desenvolvimento do capitalismo.

\section{REFERÊNCIAS}

\section{AGUlLA, J. C. Teoría Sociológica:} sistematización histórica. Buenos Aires: Depalma, 1987.

ARGÜELLO, K. O Ícaro da Modernidade: direito e política em Max Weber. São Paulo: Acadêmica, 1997.

ARON, R. As etapas do pensamento sociológico. São Paulo: Martins Fontes, 1987.

ARAÚJO, I. L. Foucault e a Crítica do Sujeito. Curitiba, UFPR, 2001.

DELEUZE, G. Conversações, 1972-1990. Rio de Janeiro: Ed. 34, 2000. 
DELEUZE, G. e GUATTARI, F. Mil Platôs capitalismo e esquizofrenia vol. 1. São Paulo: Ed. 34, 2002a.

DELEUZE, G. e GUATTARI, F. Mil Platôs capitalismo e esquizofrenia vol. 2. São Paulo: Ed. 34, 2002b.

DELEUZE, G. e GUATTARI, F. Mil Platôs capitalismo e esquizofrenia vol. 3. São Paulo: Ed. 34, 2002c.

DELEUZE, G. e GUATTARI, F. Mil Platôs capitalismo e esquizofrenia vol. 4. São Paulo: Ed. 34, 2002d.

DELEUZE, G. e GUATTARI, F. Mil Platôs capitalismo e esquizofrenia vol. 5. São Paulo: Ed. 34, 2002e.

DREIFUS, R. Poder, Estado e Força: uma leitura de Max Weber. 2. ed. Petrópolis: Vozes, 1993.

ESOPO. The Fables of AEsop. London: The Folio Society, 1998.

FONSECA, R. M. Modernidade e Contrato de Trabalho: do sujeito de direito à sujeição jurídica. São Paulo: LTr, 2002.

FOUCAULT, M. Resumo dos Cursos do Collège de France (1970-1982). Rio de Janeiro: Jorge Zahar, 1997.

FOUCAULT, M. Em Defesa da Sociedade: curso no Collège de France (1975-1976).

São Paulo: Martins Fontes, 2000.

FOUCAULT, M. A Verdade e as Formas Jurídicas. 2. ed. Rio de Janeiro: Nau, 2001.
FOUCAULT, M. Os Anormais: curso no Collège de France (1974-1975). São Paulo: Martins Fontes, 2002.

FOUCAULT, M. Ditos e Escritos IV estratégia, poder-saber (org. Manoel Barros da Motta). Rio de Janeiro: Forense, 2003.

FOUCAULT, M. Microfísica do Poder. 19. ed. São Paulo: Graal, 2004a.

FOUCAULT, M. Vigiar e Punir. 28. ed. Petrópolis: Vozes, 2004b.

FREUND, J. Sociologia de Max Weber. 4. ed. Rio de Janeiro: Forense, 1987.

GUANDALINI JR., W.; MONTOYA, D. K. O Sujeito de Direito e o Novo Código Civil desonra ou Harpias?, disponível em 2 de outubro na página da web $<$ http:// www.historiadodireito.com.br/textos/ sujeito\%20de\%20direito.htm>. 2003.

PIERUCCI, A. F. $O$ desencantamento do mundo: todos os passos do conceito em Max Weber. São Paulo: Ed. 34, 2003.

RAGO, M. et alii. (Orgs.). Imagens de Foucault e Deleuze: ressonâncias nietzschianas. Rio de Janeiro: DP\&A, 2002.

WEBER, M. Metodologia das Ciências Sociais. São Paulo: Cortez, 1995.

WEBER, M. A Ética Protestante e o "Espírito" do Capitalismo. São Paulo: Companhia das Letras, 2004. 